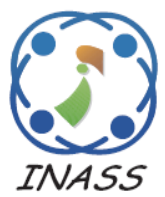

\title{
A New Control Strategy for Three Phase Grid Connected PV System Under Severe Partial Shading Conditions
}

\author{
Mohamed Bahri ${ }^{1 *}$ \\ Mohamed Talea ${ }^{1}$ \\ Hicham Bahri $^{1}$ \\ Mohamed Aboulfatah ${ }^{2}$ \\ ${ }^{I}$ Information Processing laboratory, Faculty of Science Ben M'Sik, Hassan II University of Casablanca, Morocco \\ ${ }^{2}$ Mathematics, Informatics, Engineering Science laboratory; Physics Department, Faculty of Science and \\ Technologies, University Hassan I, Settat, Morocco \\ * Corresponding author's Email: m.bahri@uhp.ac.ma
}

\begin{abstract}
Photovoltaic energy is one of the most usable renewable energy on earth, however it is highly affected by several parameters such as irradiance and temperature which directly affect its efficiency, especially in the presence of PSC (partial shading condition) which generates multiple power peaks consisting of one high global maximum called GMPP (global maximum power point) and other lower local maximum called LMPP (local maximum power point). Under this condition, conventional techniques such as $\mathrm{P} \& \mathrm{O}$ (Perturb \&Observe), IC (Incremental conductance) and nonlinear controllers fail to track the GMPP and are trapped in one of the LMPP which can be the lower peak, thus, provoking a significant drop in power. This paper presents a new control strategy for three phase grid connected PV system based on ANN (artificial neural network) for GMPPT (GMPP tracking) under PSC. The proposed approach was compared to the latest GMPPT algorithms. Results showed the good performance of the proposed controller in tracking speed with $0.0045 \mathrm{~s}$, high precision of $99.73 \%$ with negligible oscillations around GMPP of $0.01 \mathrm{~W}$. In addition, a classical controller was used to control the three phase inverter in order to inject a synchronized sinusoidal current to the grid with a low THD (total harmonic distortion) ratio of $1.23 \%$. The overall system worked perfectly under severe partial shading conditions.
\end{abstract}

Keywords: Photovoltaic system, GMPPT, ANN, Partial shading conditions, Grid connected, Synchronization.

\section{Introduction}

In recent years, the diminishing of fuel based sources along with high demand in energy, has provoked an unprecedented research race for alternative clean long term energy. One of the best alternatives of renewable energy sources is photovoltaics PV due to their reliability, safe power delivery and relative ease to implement and maintain [1]. However, because of the low power ratio delivered by these PVs, which is around 20\%, extracting maximum power has gone extensive research activity to find the best methods for MPPT [2]. Indeed, various MPPT algorithms were recommended in literature to extract the maximum available power from the PV system [3, 4]. In fact, by efficiently tracking the MPP, the system is forced to operate in optimum mode thus increasing its overall efficiency and minimizing power losses. However, finding MPP is not always an easy task, due to the nonlinearity of the P-V curve[5]. Furthermore, other varying parameters like temperature and irradiance change can affect the MPP search [6]. Different techniques, Classical, nonlinear and other strategies were used to track MPP like perturb and observe $\mathrm{P} \& \mathrm{O}$ [7], incremental conductance IC [8] and backstepping algorithm [9] which are well known in literature with good tracking performance and response time. However, these techniques faces serious limitations and became ineffective when partial shading condition occurs. PSC occurs when solar irradiations are being blocked by clouds, building and others blocking items [10], and it generates multiple peaks called local maximum power point LMPP and one GMPP representing the maximum power of the P-V curve[11-13]. Under 


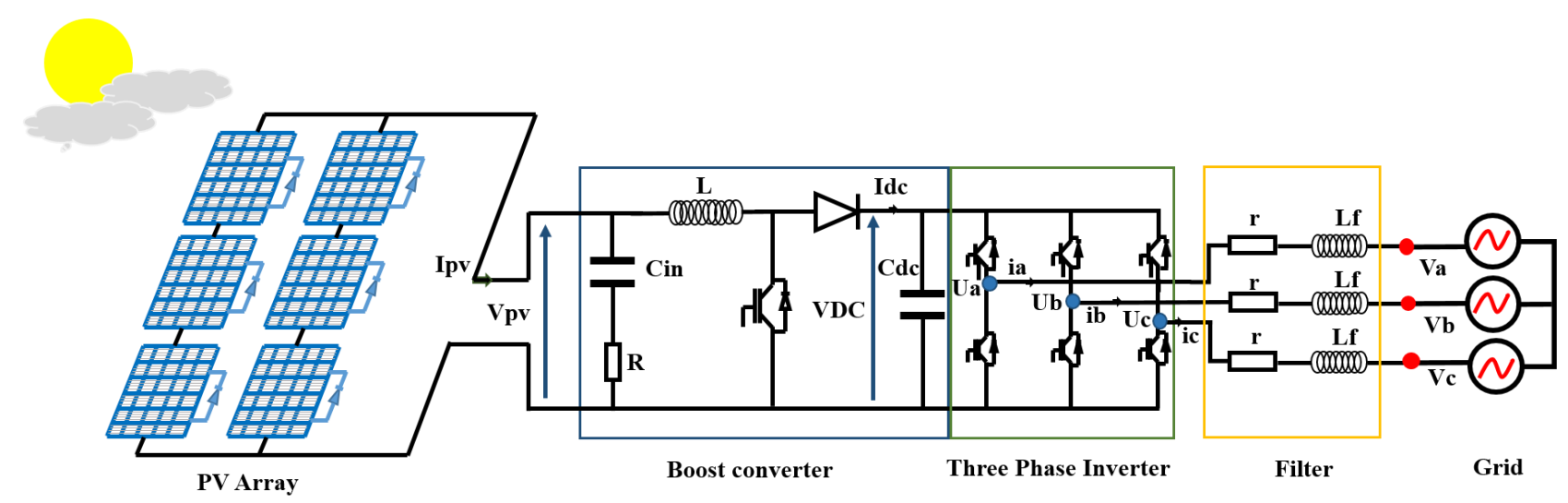

Figure. 1 Schematic diagram of the grid connected PV system

PSC, these techniques are enable to correctly track the GMPP and are stuck in one of these LMPP resulting in a poor performance and significant loss of the PV power[3, 14].

Several algorithms were proposed in literature to track the GMPP and to address the above problems of classical techniques. The first solution to correctly track the GMPP was the implementation of a searching algorithm into the classical $\mathrm{P} \& \mathrm{O}$ [15], in fact the searching algorithm manages to search for all maximums which after a comparison saves the coordinates near the GMPP which are transmitted to the P\&O that manages to track the GMPP. Although the modified $\mathrm{P} \& \mathrm{O}$ manages to correctly track the GMPP, it is too slow in response time because of high oscillation in the transient regime, also clear oscillations were present around the GMPP. Other GMPPT Algorithms are present in recent literature.

A FL (fuzzy logic) based grey wolf optimization GMPPT for micro-grid under partial shading condition was introduced by [5], the new FL outperformed the standard $\mathrm{P} \& \mathrm{O}$ and $\mathrm{FL}$ with an accuracy of $99.97 \%$ and a tracking time of 0.038 s.

Recently, metaheuristics optimization techniques emerged and are widely tested in PV systems to track GMPP under PSC. Researchers of [16] proposed a particle swarm optimization PSO combined with sliding mode control SMC for off grid PV system under PSC. Results demonstrates the good performance of the method with good efficiency and response time, although the simulation wad done under PSC the result of response time concerns only the normal shading and not PSC. Another optimization technique Henry gas optimization for MPPT was used in [17], results showed a tracking speed of $0.12 \mathrm{~s}$ and $99.86 \%$ efficiency. Basically, other than their complex model and long processing time, optimization algorithms are randomly initialized in population and particles search which pushes the system to iterate repeatedly inducing that one place may be explored more than once, hence increasing the response time for MPPT, in addition these algorithms works with constant tuning parameters that varies with the PV size, and are based on a trial and error approach which is not precise and may degrade the overall power efficiency [18]. For that reason AI based techniques represent the best choice for GMPPT, because they depend only on the database of input parameters and training data which enhances the robustness of the algorithm over other varying external and internal parameters. Furthermore, the more data AI algorithms get the more precise they become.

In this paper we present a new control strategy for three phase grid connected PV system based on ANN for GMPPT under PSC, which overcomes all limitations that hinders classical methods especially tracking GMPPT under PSC, and proved that the application of ANN algorithm for GMPPT can perform better than the existing state of art algorithms.

For the second part of the system, we have chosen the grid connected topology due to its advantages over battery PV systems which are limited in power, cumbersome and needs additional cost and monitoring [19, 20]. Besides, integration of grid connected PV system improves the economics of theses PVs by reducing operational cost, optimizing the energy building, thus improving quality life.

For this matter, a direct control method was applied on the three phase inverter, in order to synchronize the injected inverter current to the grid with an inductive filter to reduce harmonic distortions hence providing a good power quality.

The paper is organized as follow: The first section present the introduction, the second section describes the system and model chosen for this work. In Section 3 , the proposed control strategy is presented and analysed. Then the decoupled control for the three phase grid connected PV system is shown in the same section. Section 4 is focused on simulation results and discussion and finally we present the conclusion and the future prospects of our work in section 5 . 


\section{System description and modelling}

The proposed system is shown in Fig. 1, it consists of $6 \mathrm{PV}$ panels interconnected in series and parallel, delivering a maximum power of $160 \mathrm{~kW}$ at standard atmospheric conditions. In order to extract the maximum power from the PV system, a DC-DC boost converter is chosen. Vpv and Ipv are the PV voltage and current, $\mathrm{Cin}=0.01 \mathrm{~F}$ and $\mathrm{Cdc}=3227 \mu \mathrm{F}$ are respectively the input and the output capacitors of the boost converter with $R=7 \mathrm{~m} \Omega, L=0.4 \mathrm{mH}$ is the boost converter inductor. For the third part, a PWM based inverter is controlled to deliver a synchronized power to the grid. The RL filter is used to filter out harmonics and to respect interconnection rules between the voltage sources. $\mathrm{Lf}=1.1 \mathrm{mH}$ and $\mathrm{r}=0.06$ $\Omega$, for the low pass filter. The control parameters are $\mathrm{f}=20 \mathrm{KHz}$ for the switching frequency, the PI proportional coefficient is 10 and the PI integral coefficient is 20.

We assume that the three phase grid voltage $\left(\mathrm{V}_{\mathrm{a}}\right.$, $\mathrm{V}_{\mathrm{b}}, \mathrm{V}_{\mathrm{c}}$ ) is balanced and could be represented by the equations:

$$
\begin{aligned}
& V a=V \cos (\omega t) \\
& V b=V \cos \left(\omega t-\frac{2 \pi}{3}\right) \\
& V c=V \cos \left(\omega t+\frac{2 \pi}{3}\right)
\end{aligned}
$$

Where $\mathrm{V}$ is the peak voltage of three phase grid, $\omega$ is the grid pulsation. By applying the Kirchhoff's Law, the relation between the three phase grid and the inverter can be represented as in Eq. (4) as follows:

$$
\left(\begin{array}{l}
\frac{d i a}{d t} \\
\frac{d i b}{d t} \\
\frac{d i c}{d t}
\end{array}\right)=\left(\begin{array}{ccc}
-\frac{R}{L} & 0 & 0 \\
0 & -\frac{R}{L} & 0 \\
0 & 0 & -\frac{R}{L}
\end{array}\right)\left(\begin{array}{l}
U a-V a \\
U b-V b \\
U c-V c
\end{array}\right)
$$

Eq. (4) is presented in three phase frame, the use of a dq transformation is justified to obtain the equation in synchronous rotating dq reference for the purpose of reducing the number of equations and complex calculations, as shown in Eq. (5):

With
Table 1. PV module specifications

Maximum power point(MPP)

Open circuit voltage (VOC)

Short circuit current (ISC)

Maximum power point voltage (VMP)

Maximum power point current (IMP)

$\mathrm{T}=\sqrt{\frac{2}{3}}\left[\begin{array}{ccc}\cos (\theta) & \cos \left(\theta-\frac{2 \pi}{3}\right) & \cos \left(\theta+\frac{2 \pi}{3}\right) \\ -\sin (\theta) & -\sin \left(\theta-\frac{2 \pi}{3}\right) & -\sin \left(\theta+\frac{2 \pi}{3}\right)\end{array}\right]$

Where $\mathrm{T}$ represents the transformation matrix from abc frame to dq frame, $\theta=\omega t$ is the grid angular frequency, $\mathrm{t}$ is the time variable. The coefficient $\sqrt{\frac{2}{3}}$ is used to preserve the same power magnitude.

$$
\begin{aligned}
\left(\begin{array}{c}
\frac{d i d}{d t} \\
\frac{d i q}{d t}
\end{array}\right)= & \frac{1}{L}\left(\begin{array}{cc}
-R & \omega \\
-\omega & -R
\end{array}\right)\left(\begin{array}{c}
i d \\
i q
\end{array}\right)-\frac{1}{L}\left(\begin{array}{l}
V d \\
V q
\end{array}\right) \\
& +\frac{V d c}{L}\left(\begin{array}{l}
U d \\
U q
\end{array}\right)
\end{aligned}
$$

Where $\mathrm{Vd}$ and $\mathrm{Vq}$ are the grid voltage in dq axis, (id, iq) and (Ud, Uq) are respectively the output current and voltage of the inverter in dq axis.

Using (Eq. (5)) the expression of the inverter voltage in $\mathrm{dq}$ axis is given by:

$$
\begin{aligned}
& U d=\frac{1}{V d c}\left(\frac{L d i}{d t}+R i d-\omega L i q+V d\right) \\
& U q=\frac{1}{V d c}\left(\frac{L d i q}{d t}+R i q+\omega L i d+V q\right)
\end{aligned}
$$

\section{Controller design}

There are two parts of the system that needs control. First, and in order to track the GMPP from the PV system, a new control strategy for three phase grid connected PV system applying ANN algorithm for GMPPT under PSC is elaborated. The second part of this work is to control the three phase inverter with a simple and efficient control strategy that manages to regulate the DC-DC link voltage and to inject a good synchronized quality power into the grid.

\subsection{MPPT controller}

The presence of PSC induces multiple peaks in the P-V curves by generating multiple maximum which are commonly called LMPP and one GMPP which represent the highest peak power in the P-V curve. In order to force the PV system to work in 


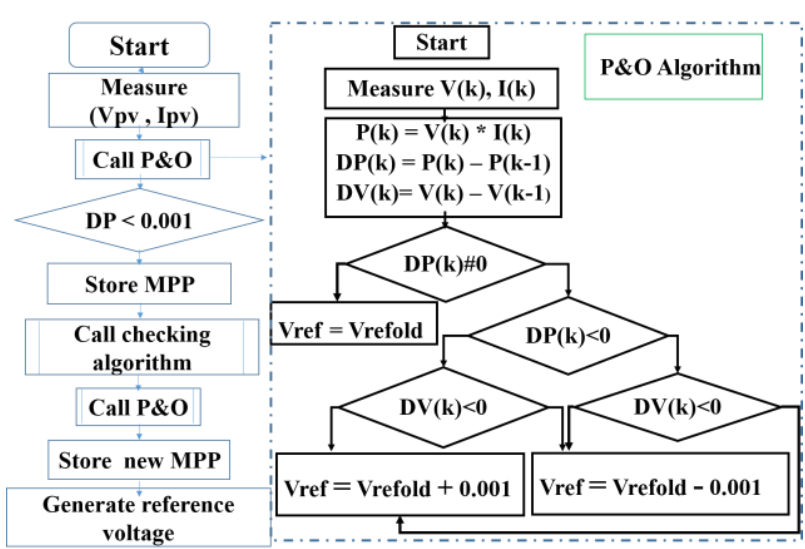

Figure. 2 Flowchart of the modified $\mathrm{P} \& \mathrm{O}$

Table 2. ANN database generated

\begin{tabular}{|c|c|c|c|c|c|c|}
\hline \multicolumn{6}{|c|}{ Irradiances } & \multirow{2}{*}{$\begin{array}{c}\text { Output } \\
\text { Voltage } \\
\text { Vmpp } \\
\end{array}$} \\
\hline G1 & $\mathrm{G} 2$ & G3 & G4 & G5 & G6 & \\
\hline 500 & 500 & 1000 & 1000 & 500 & 1000 & 252.2 \\
\hline 250 & 500 & 1000 & 250 & 500 & 1000 & 167.8 \\
\hline 800 & 800 & 800 & 800 & 800 & 800 & 237.5 \\
\hline 100 & 800 & 800 & 800 & 800 & 800 & 164.5 \\
\hline 400 & 200 & 250 & 600 & 200 & 150 & 249.8 \\
\hline 400 & 400 & 400 & 1000 & 1000 & 1000 & 236.3 \\
\hline$\cdots$ & $\ldots$ & $\cdots$ & $\cdots$ & $\cdots$ & $\cdot$ & $\cdots$ \\
\hline 400 & 500 & 1000 & 400 & 500 & 1000 & 254.3 \\
\hline 800 & 500 & 1000 & 800 & 500 & 1000 & 255.8 \\
\hline 1000 & 1000 & 1000 & 1000 & 1000 & 1000 & 236.4 \\
\hline
\end{tabular}

optimum mode, the GMPP must be tracked at all times, for this reason several GMPPT algorithm were developed. The classical P\&O can normally track the MPP but fails in the case of PSC. To solve this issue a modified $\mathrm{P} \& \mathrm{O}$ was proposed by combining a searching algorithm with the classic $\mathrm{P} \& \mathrm{O}$, the modified algorithm tracked correctly the GMPP with a slow response time and clear oscillations around the GMPP. To enhance the overall performances of the PV system by increasing the response time and minimizing the oscillation, a GMPPT based on ANN algorithm is proposed.

\subsubsection{Perturb and observe algorithm}

The P\&O MPPT algorithm works based on the derivative of the PV power and voltage $\frac{d P p v}{d V p v}$ if its sign is positive that means the MPP is not yet reached, if the sign is negative that means that we already passed the MPP, but if the result is equal to zero that means the MPP is reached. The working of the $\mathrm{P} \& \mathrm{O}$ is demonstrated in Fig. 2. The major drawback of this technique is that it cannot track the GMPP under partial shading condition.

\subsubsection{Modified perturb and observe algorithm:}

In order to resolve the issue of the classic $\mathrm{P} \& \mathrm{O}$ in not tracking the GMPP under PS, a searching algorithm was implemented into it. The flowchart of this modified P\&O is present in Fig. 5. The new modified $\mathrm{P} \& \mathrm{O}$ manages to track the GMPP under varying PS, but the transient regime is too long which reduces the response time, in addition clear oscillations were present around the GMPP which lowers the overall efficiency of this techniques.

\subsubsection{Proposed GMPPT controller}

The first control loop consist of an ANN GMPPT algorithm that is able to instantly generate the reference voltage Vmpp which is then compared to the actual voltage from the PV panels, the error is then put to a PI controller and then transformed into a PWM signal that controls the boost converter in order to force the PV panel to work in the maximum power of the $\mathrm{P}-\mathrm{V}$ curve. The main advantage of the proposed control strategy over the conventional methods is to overcome their biggest weakness of not tracking the global maximum (GMPP) under partial shading condition. The used ANN algorithm is derived from the working of the human neurons brain that can process any given information. The design of this ANN was done by following these steps. The first thing is generating the database which was provided offline from simulations of multiple P-V curves (1483 P-V curves) under various PSC with the same parameters of the boost converter. Then, the coordinates of the GMPP corresponding to each PS scenario are extracted. The data collected is then stored in a table to constitute the database of the ANN algorithm, see Table 1. Secondly, the ANN network was created with the MATLAB toolbox using the command "nnstart", we choose the fitting app and the database created for this purpose, the next step consist of selecting the number of layers and neurons in each layer, which in this work is one input layer with six inputs from six irradiances sensors, one hidden layer with ten neurons and one output layer representing the Vmpp reference voltage, see Fig. 3. After that comes the training algorithm which is the levenberg-marquardt, the training was done with $70 \%$ of data, then evaluating the results using regression analyses and MSE (mean square error) with $30 \%$ of data, as in Fig. 4.

\subsection{Inverter controller}

A classical control was used to regulate the DC voltage and to control the three phase inverter. Eqs. 




Figure. 3 The used ANN structure
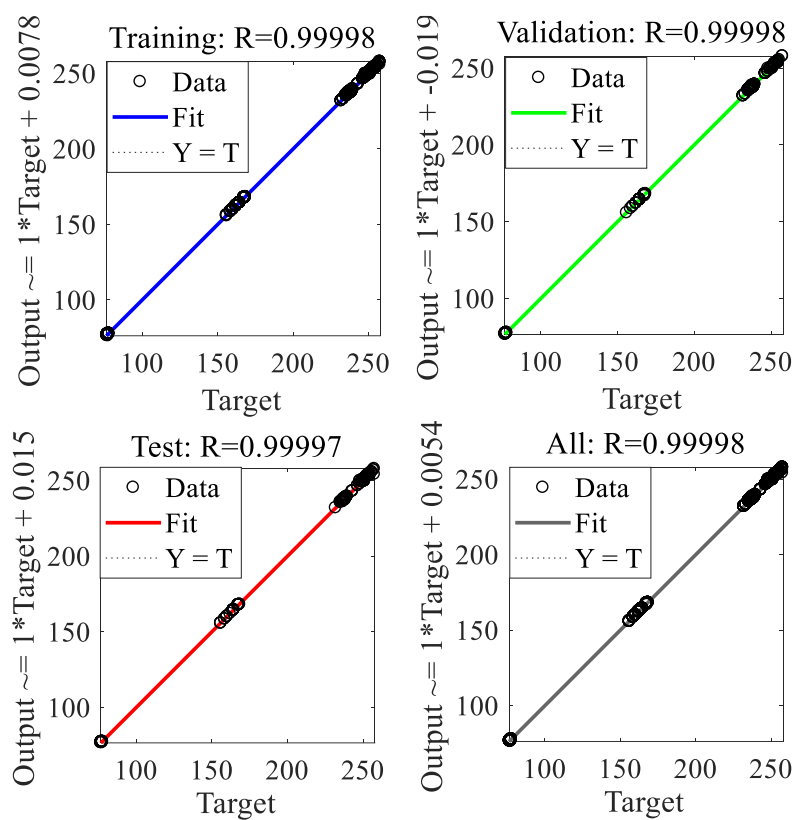

Figure. 4 ANN test, validation and results

Table 3. Simulated PSC

\begin{tabular}{|c|c|c|c|c|}
\hline PSC scenarios & $\begin{array}{l}\text { Time } \\
(\mathrm{s})\end{array}$ & $\operatorname{VMP}(\mathrm{V})$ & $\begin{array}{l}\text { IMP } \\
\text { (A) }\end{array}$ & $\begin{array}{l}\text { GMPP } \\
\times 10^{4} \mathrm{~W}\end{array}$ \\
\hline $\begin{array}{c}\text { PS1:[500 } 5001000 \\
10005001000]\end{array}$ & $\begin{array}{l}0- \\
0.3\end{array}$ & 252.2 & 367.7 & 9.271 \\
\hline $\begin{array}{l}\text { PS2:[200 } 5001000 \\
\text { 200 } 5001000]\end{array}$ & $\begin{array}{l}0.3- \\
0.6\end{array}$ & 167.8 & 368.6 & 6.185 \\
\hline $\begin{array}{c}\text { NS:[800 } 800800 \\
\text { 800 800 800] }\end{array}$ & $\begin{array}{c}0.6- \\
0.9\end{array}$ & 239.2 & 571.4 & 13.67 \\
\hline $\begin{array}{c}\text { PS3:[100 } 800800 \\
800800800]\end{array}$ & $\begin{array}{c}0.9- \\
1.2\end{array}$ & 164.5 & 574.3 & 9.447 \\
\hline
\end{tabular}

(6) and (7) indicates the coupling of dq axis control.

The decoupling and stability in closed loop control are satisfied with the use of a PI regulator as shown in Eqs. (8) and (9) which represent the controller output signal, the complete schematic diagram of this control strategy is shown in Fig. 3:

$$
\begin{gathered}
C d=\frac{1}{V d c}\left[\left(K p+\frac{K i}{s}\right)\right](i d r e f-i d)- \\
\omega L i q+V d] \\
C q=\frac{1}{V d c}\left[\left(K p+\frac{K i}{s}\right)\right](i q r e f-i q)+ \\
\omega L i d+V q]
\end{gathered}
$$

The next section is dedicated to validate the performances of the proposed control strategy.

\section{Simulation results and discussion:}

A two stages three phase grid connected PV system is simulated in MATLAB/SIMULINK 2017a for a duration of $1.2 \mathrm{~s}$. The solar farm used has two parallel set of three series PV panels and delivers a maximum power of $160 \mathrm{KW}$. The simulated partial shading scenarios are given in Table 3 , and considers all difficult shading patterns when the GMPP (highest peak) is located in the first peak as in PS3 scenario, middle peak as in PS2 or last peak as in PS1. Also the $\mathrm{P}-\mathrm{V}$ curves of these scenarios are shown in Fig 6 (a). The presence of LMPPs is overcome with our proposed ANN GMPPT algorithm. Results given in Fig 6 (b), show that the proposed method successfully tracked the GMPP under varying normal or difficult partial shading condition. Fig. 7 (a) present a zoomed view of the results, in the first scenario the $P \& O$ MPPT fail to track the GMPP and is stuck in the second peak, the modified $\mathrm{P} \& \mathrm{O}$ manages to track the GMPP but with high oscillations and slow response time of $0.025 \mathrm{~s}$ while the proposed ANN GMPPT reaches the GMPP in $0.0064 \mathrm{~s}$ with a precision of 99.71\%. In Figs. 7 (b) and (c) the P\&O accidentally manages to track the GMPP but with low response time and high oscillations. The ANN GMPPT continue to show best results with a response time of $0.0045 \mathrm{~s}$. In order to show the good precision of the proposed ANN GMPPT, Fig. 7 (d) compares the oscillations around the GMPP. While the P\&O fails again to track the GMPP, the modified $\mathrm{P} \& \mathrm{O}$ present high oscillations with negligible ones for the ANN GMPPT. Furthermore, in all presented scenarios the proposed algorithm is faster than all the algorithms presented in literature as demonstrated in Table 4, with a response time of $0.0045 \mathrm{~s}$ in best response time 


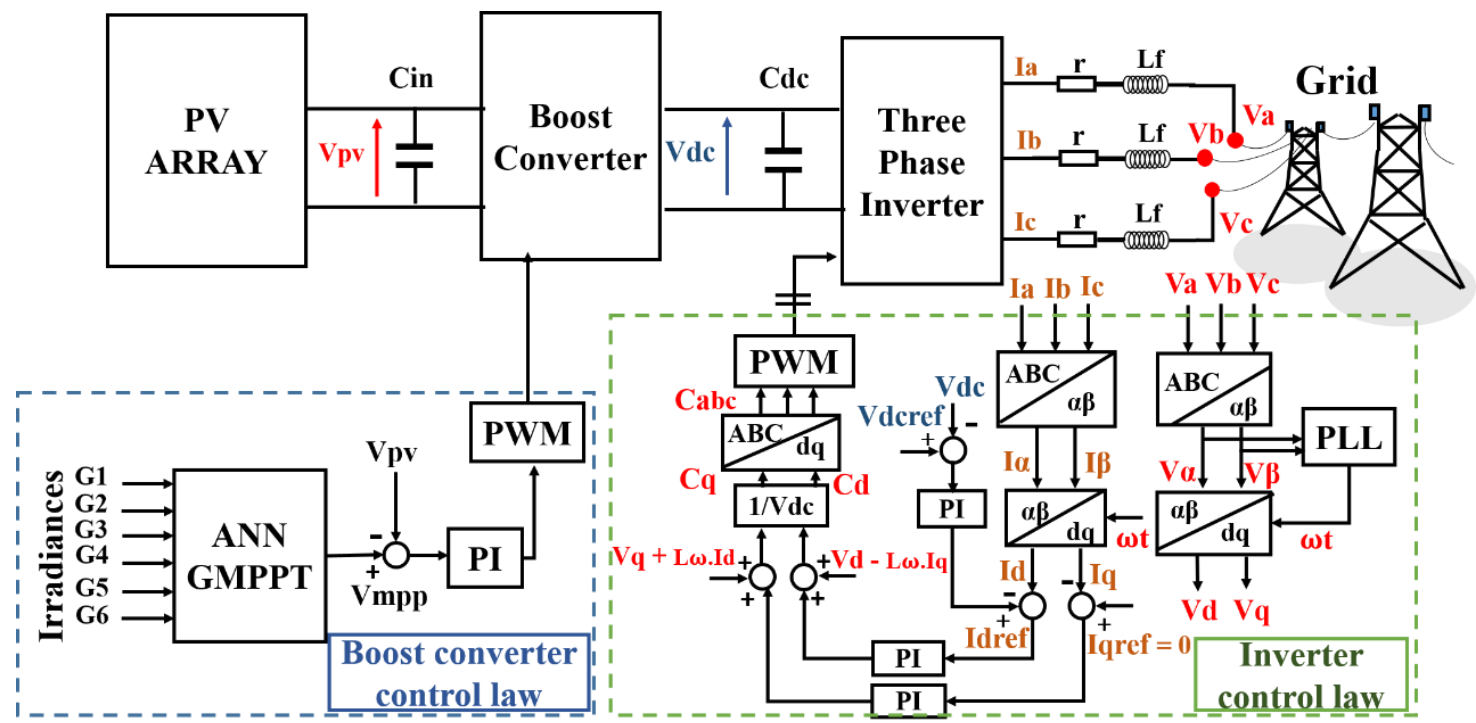

Figure. 5 Proposed control strategy

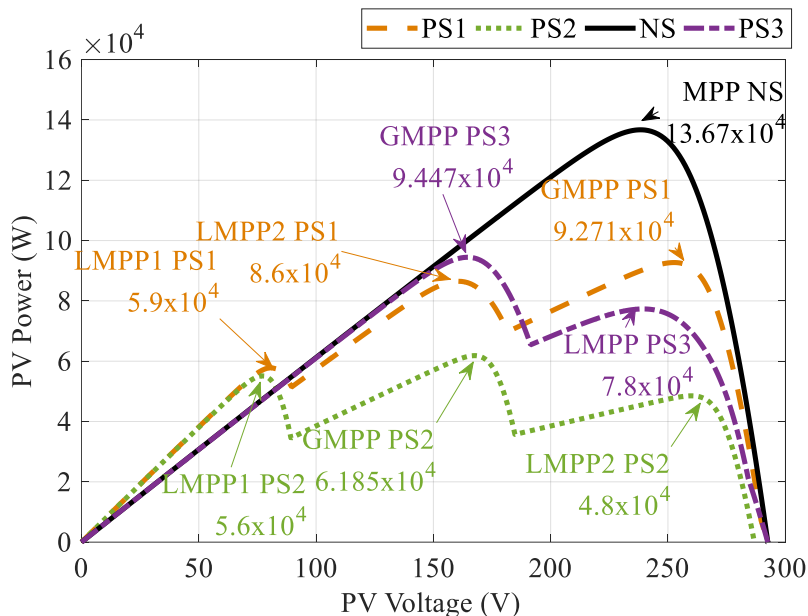

(a)

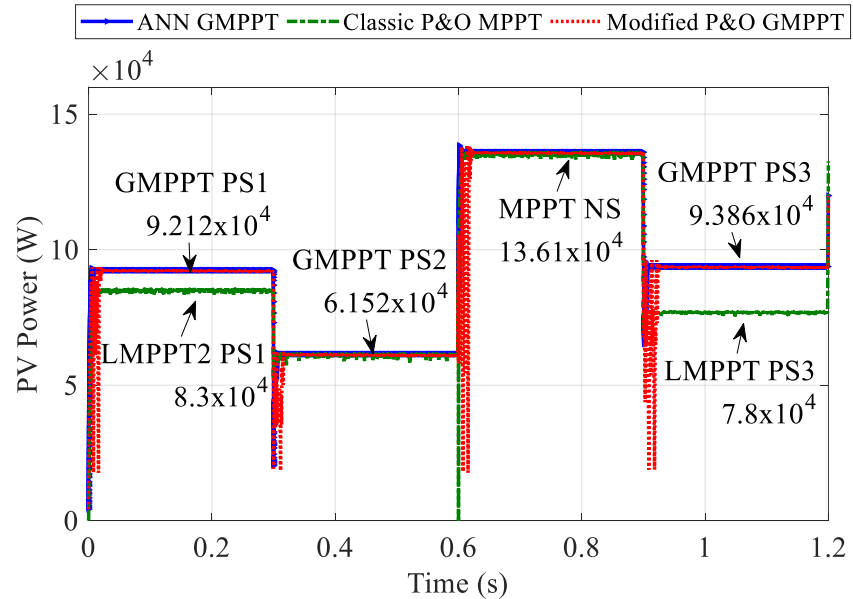

(b)

Figure. 6: (a) Different partial shading scenarios and (b) GMPPT of PV Power under varying partial shading

scenario and $99.73 \%$ for the best efficient scenario, which makes it very fast and precise. The output boost converter voltage is very well regulated around the reference value of $600 \mathrm{~V}$ as demonstrated in Fig. 8. On the other hand, Fig. 9 shows that the inverter current is successfully synchronized with the grid voltage, with very low THD of $1.23 \%$ as in Fig. 10 . The successful decrease in THD is also due to the use of ANN GMPPT algorithm, indeed the output signal from the Boost converter has minimal oscillations around GMPP which simplifies the role of the inverter in converting this power into a good sinusoidal signal.

Results presented in Table 4, shows an excellent performance of our control strategy. Besides, the proposed ANN GMPPT is efficient, precise with very fast response time than recent algorithms. Besides, it is worth noting that in contrast of GMPPT algorithms present in literature which applied reduced power, the proposed method presented in this paper, was applied in a three phase grid connected PV system which demand high power of over $100 \mathrm{KW}$ which explains the small difference in efficiency, while for the response time, the proposed method is faster than the other GMPPT algorithms.

The GMPPT is tracked for all cases of severe partial shading conditions, the boost converter output voltage is regulated around the reference value, and the inverter current is well synchronized to the grid. Consequently, the proposed ANN GMPPT algorithm with the classical control method of the three phase inverter are fast, efficient and precise with negligible oscillation, and very low THD. The overall system performs perfectly under difficult shading conditions. 


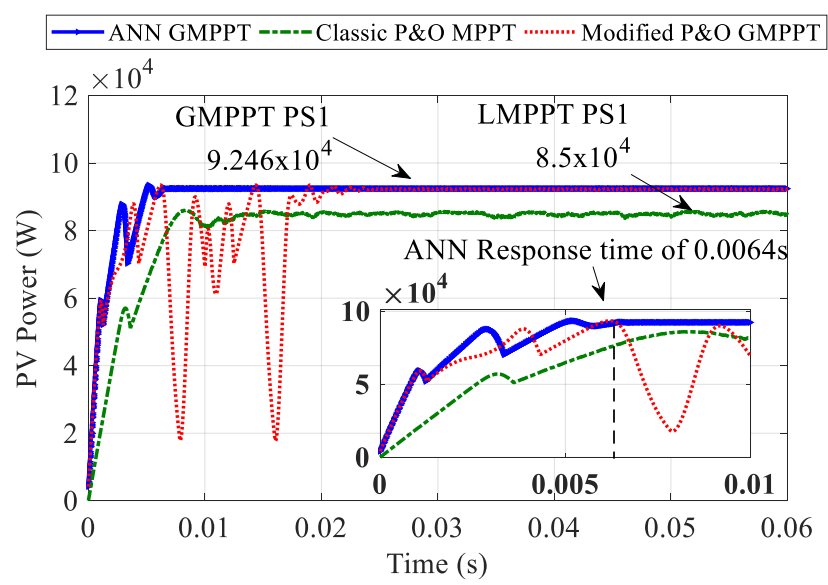

(a)

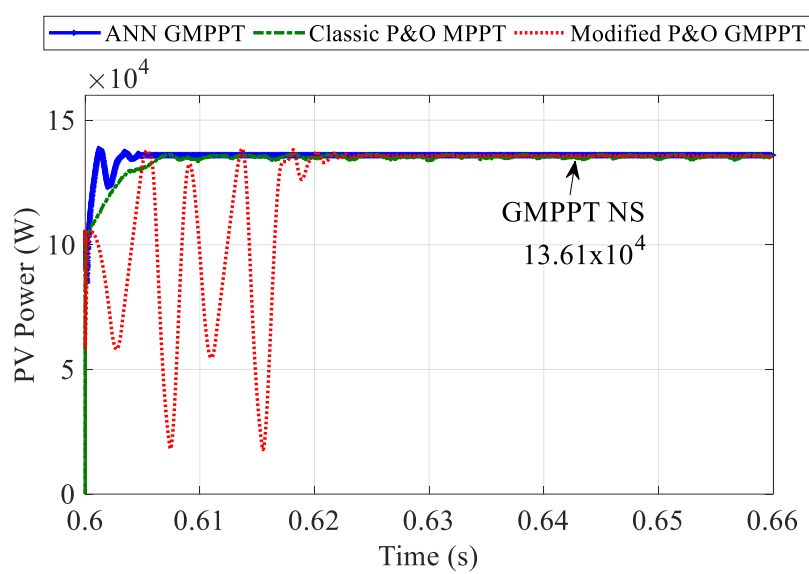

(c)

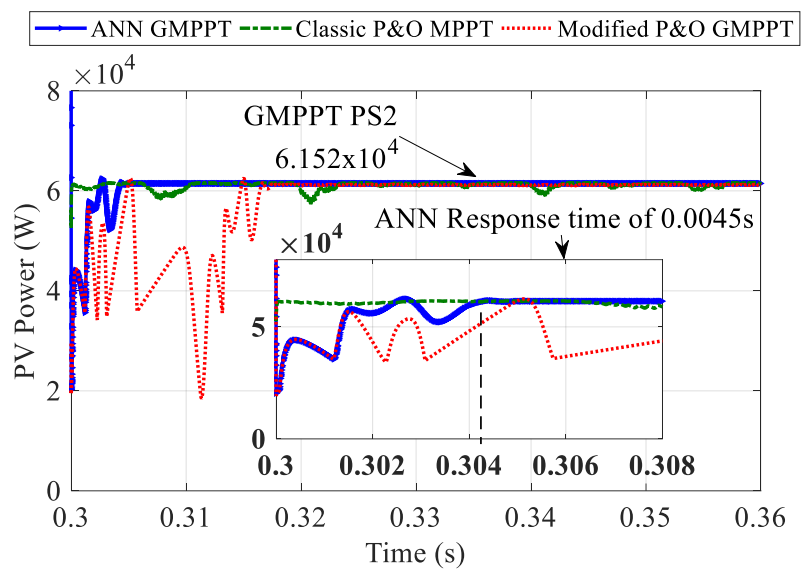

(b)

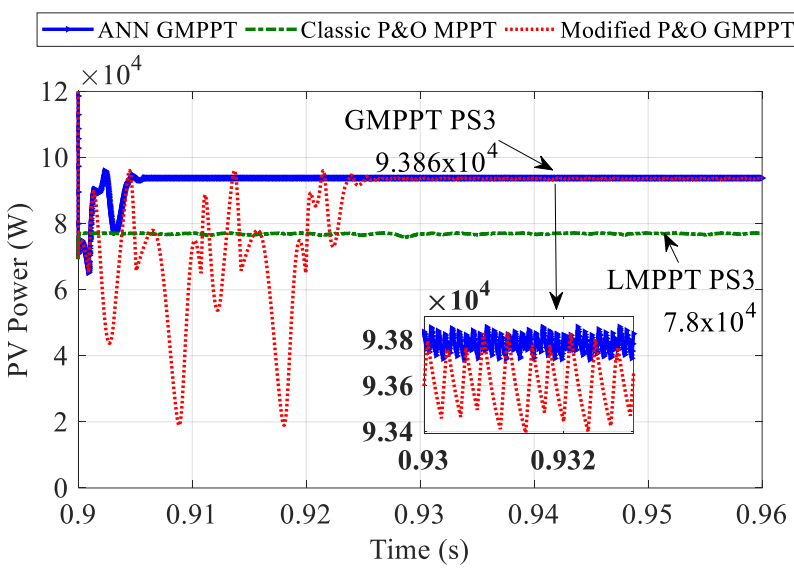

(d)

Figure. 7 Zoom on GMPPT of PV power under each partial shading scenario: (a) PS1, (b) PS2, (c) NS, and (d) PS3

Table 4. Results of the simulated normal and partial shading conditions

\begin{tabular}{|c|c|c|c|c|c|}
\hline Algorithms & Cases & $\begin{array}{c}\text { Theoretical } \\
\text { GMPP } \\
(\mathbf{W})\end{array}$ & $\begin{array}{c}\text { Obtained } \\
\text { GMPP }(\mathbf{W})\end{array}$ & $\begin{array}{c}\text { Efficiency } \\
(\%)\end{array}$ & $\begin{array}{c}\text { Tracking speed } \\
(\mathbf{s})\end{array}$ \\
\hline \multirow{3}{*}{ Proposed ANN } & PS1 & $9.271 \times 10^{4}$ & $9.246 \times 10^{4}$ & 99.73 & 0.0064 \\
GMPPT & PS2 & $6.185 \times 10^{4}$ & $6.152 \times 10^{4}$ & 99.46 & 0.0045 \\
& PS3 & $13.67 \times 10^{4}$ & $13.61 \times 10^{4}$ & 99.56 & 0.0045 \\
& $9.447 \times 10^{4}$ & $9.386 \times 10^{4}$ & 99.30 & 0.005 \\
\hline & PS1 & $9.271 \times 10^{4}$ & $9.244 \times 10^{4}$ & 99.60 & 0.025 \\
Modified P\&O & PS2 & $6.185 \times 10^{4}$ & $6.149 \times 10^{4}$ & 99.41 & 0.018 \\
& NS & $13.67 \times 10^{4}$ & $13.61 \times 10^{4}$ & 99.56 & 0.024 \\
& PS3 & $9.447 \times 10^{4}$ & $9.375 \times 10^{4}$ & 99.24 & 0.026 \\
\hline P\&O & PS1 & $9.271 \times 10^{4}$ & $8.5 \times 10^{4}$ & 91.68 & 0.015 \\
& PS2 & $6.185 \times 10^{4}$ & $6.149 \times 10^{4}$ & 99.41 & 0.01 \\
& NS & $13.67 \times 10^{4}$ & $13.61 \times 10^{4}$ & 99.56 & 0.008 \\
\hline FL-GWO [5] & PS3 & $9.447 \times 10^{4}$ & $7.7 \times 10^{4}$ & 81.50 & 0.006 \\
\hline VSPO [4] & & & & 9.89 \\
\hline
\end{tabular}




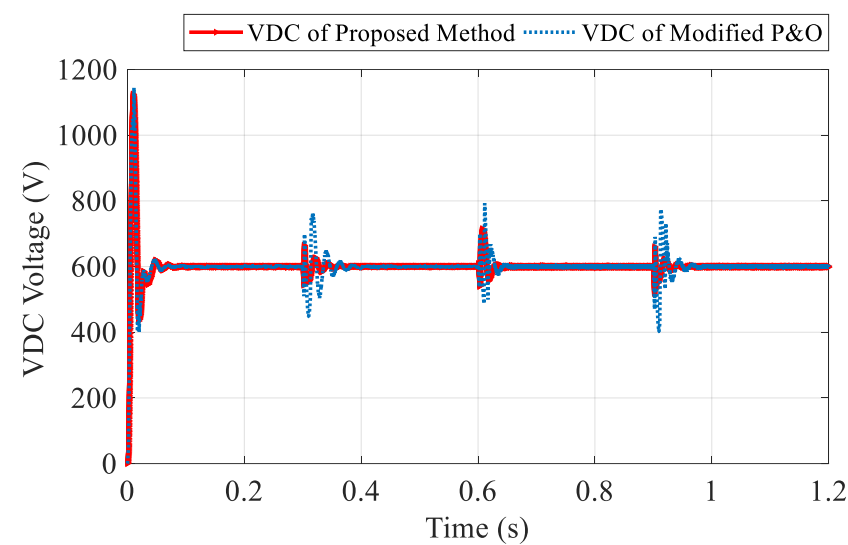

Figure. 8 Regulated DC voltage

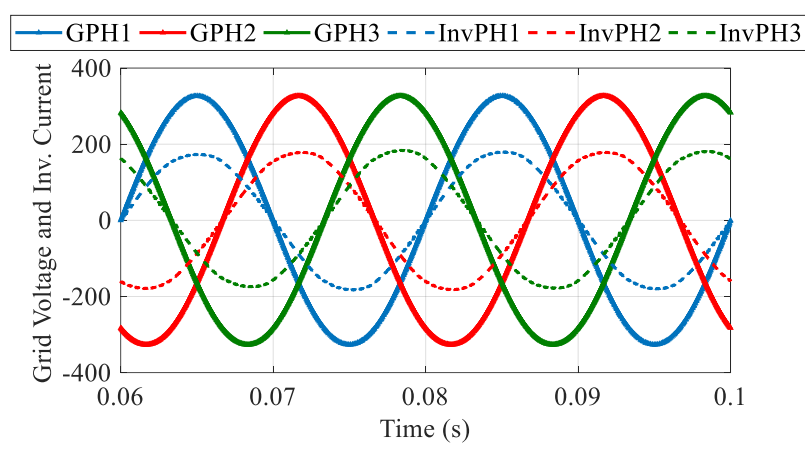

Figure. 9 Grid voltage and inverter current

\section{Conclusion}

This paper proposed a new control strategy for three phase grid connected PV system using ANN algorithm for the Boost Converter and a decoupled control law of the inverter. The goal of this strategy is to realize GMPPT under normal and partial shading conditions and injecting this PV power into the grid with a good quality. The simulated results proved the good performances of the elaborated MPPT control method in response time and efficient tracking compared with existing GMPPT algorithms. Moreover, the decoupled control law drove the inverter to inject a three phase current into the grid with a good synchronization and low THD of $1.23 \%$. The future works will focus on applying these findings in practical work.

\section{Conflicts of interest}

The authors declare no conflict of interest.

\section{Author contributions}

Mohamed Bahri, as the corresponding author, has designed and simulated the proposed GMPPT controller using Matlab/Simulink and written the


DC component Fundamental THD

$$
\begin{aligned}
& =0.008516 \\
& =263.1 \text { peak (186.1 rms) } \\
& =1.23 \%
\end{aligned}
$$

$\begin{array}{rr}0 \mathrm{~Hz} & (\mathrm{DC}): \\ 50 \mathrm{~Hz} & (\text { Fnd }): \\ 100 \mathrm{~Hz} & (\mathrm{~h} 2): \\ 150 \mathrm{~Hz} & (\mathrm{~h} 3): \\ 200 \mathrm{~Hz} & (\mathrm{~h} 4): \\ 250 \mathrm{~Hz} & (\mathrm{~h} 5): \\ 300 \mathrm{~Hz} & (\mathrm{~h} 6): \\ 350 \mathrm{~Hz} & (\mathrm{~h} 7): \\ 400 \mathrm{~Hz} & (\mathrm{~h} 8): \\ 450 \mathrm{~Hz} & (\mathrm{~h} 9): \\ 500 \mathrm{~Hz} & (\mathrm{~h} 10): \\ 550 \mathrm{~Hz} & (\mathrm{~h} 11): \\ 600 \mathrm{~Hz} & (\mathrm{~h} 12): \\ 650 \mathrm{~Hz} & (\mathrm{~h} 13): \\ 700 \mathrm{~Hz} & (\mathrm{~h} 14): \\ 750 \mathrm{~Hz} & (\mathrm{~h} 15): \\ 800 \mathrm{~Hz} & (\mathrm{~h} 16):\end{array}$

Figure. 10 THD analyses of the injected current

$\begin{array}{rr}0.00 \% & 90.0^{\circ} \\ 100.00 \% & -0.2^{\circ} \\ 0.01 \% & 206.7^{\circ} \\ 0.00 \% & -83.8^{\circ} \\ 0.00 \% & 80.3^{\circ} \\ 0.50 \% & -10.9^{\circ} \\ 0.00 \% & 101.8^{\circ} \\ 0.76 \% & 223.5^{\circ} \\ 0.00 \% & -50.3^{\circ} \\ 0.00 \% & 197.6^{\circ} \\ 0.00 \% & 158.8^{\circ} \\ 0.26 \% & 58.5^{\circ} \\ 0.00 \% & -44.7^{\circ} \\ 0.15 \% & 222.3^{\circ} \\ 0.00 \% & 193.6^{\circ} \\ 0.00 \% & 202.1^{\circ} \\ 0.00 \% & 70.4^{\circ}\end{array}$


original draft paper. Mohamed Talea supervised the written paper and provided the necessary support. Hicham Bahri has contributed to the validation of the proposed modelling system and controller design and also verified the writing and the paper organization. Mohamed Aboulfatah has supervised the written paper and provided the necessary support. All authors approved the final version.

\section{References}

[1] A. F. D. Paulo and G. S. Porto, "Evolution of collaborative networks of solar energy applied technologies", J. Clean. Prod., Vol. 204, pp. 310-320, 2018.

[2] A. Mohapatra, B. Nayak, P. Das, and K. B. Mohanty, "A review on MPPT techniques of PV system under partial shading condition", Renew. Sustain. Energy Rev., Vol. 80, No. June, pp. 854-867, 2017.

[3] A. N. M. Mohammad, M. A. M. Radzi, N. Azis, S. Shafie, and M. A. A. M. Zainuri, "An enhanced adaptive perturb and observe technique for effcient maximum power point tracking under partial shading conditions", Appl. Sci., Vol. 10, No. 11, 2020.

[4] A. A. Kamil, M. S. Nasr, and S. Alwash, "Maximum Power Point Tracking Method for Photovoltaic System Based on Enhanced Particle Swarm Optimization Algorithm Under Partial Shading Condition”, International Journal of Intelligent Engineering and Systems, Vol. 13, No. 6, pp. 241-254, 2020, doi: 10.22266/ijies2020.1231.22.

[5] B. Laxman, A. Annamraju, and N. V. Srikanth, "A grey wolf optimized fuzzy logic based MPPT for shaded solar photovoltaic systems in microgrids", Int. J. Hydrogen Energy, Vol. 46, No. 18, pp. 10653-10665, 2021.

[6] A. S. Masoum, F. Padovan, and M. A. S. Masoum, "Impact of partial shading on voltageand current-based maximum power point tracking of solar modules", IEEE PES Gen. Meet. PES 2010, 2010.

[7] N. Femia, G. Petrone, G. Spagnuolo, and M. Vitelli, "Optimization of perturb and observe maximum power point tracking method", IEEE Trans. Power Electron., Vol. 20, No. 4, pp. 963973, 2005.

[8] C. H. Lin, C. H. Huang, Y. C. Du, and J. L. Chen, "Maximum photovoltaic power tracking for the PV array using the fractional-order incremental conductance method", Appl. Energy, Vol. 88, No. 12, pp. 4840-4847, 2011.

[9] H. Bahri, M. Aboulfatah, M. Guisser, E.
Abdelmounim, and M. E. Malah, "Integral backstepping control for maximum power point tracking and unity power factor of a three phase grid connected photovoltaic system", Int. J. Electr. Comput. Eng., Vol. 7, No. 4, pp. 16711680, 2017.

[10] E. L. Meyer and E. E. V. Dyk, "Assessing the reliability and degradation of photovoltaic module performance parameters", IEEE Trans. Reliab., Vol. 53, No. 1, pp. 83-92, 2004.

[11] R. S. Pal and V. Mukherjee, "Metaheuristic based comparative MPPT methods for photovoltaic technology under partial shading condition", Energy, Vol. 212, p. 118592, 2020.

[12] H. Patel and V. Agarwal, "MATLAB-based modeling to study the effects of partial shading on PV array characteristics", IEEE Trans. Energy Convers., Vol. 23, No. 1, pp. 302-310, 2008.

[13] F. Bayrak, G. Ertürk, and H. F. Oztop, "Effects of partial shading on energy and exergy efficiencies for photovoltaic panels", J. Clean. Prod., Vol. 164, pp. 58-69, 2017.

[14] M. H. Zafar et al., "A novel meta-heuristic optimization algorithm based MPPT control technique for PV systems under complex partial shading condition", Sustain. Energy Technol. Assessments, Vol. 47, No. June, p. 101367, 2021.

[15] R. Alik and A. Jusoh, "Modified Perturb and Observe (P\&O) with checking algorithm under various solar irradiation", Sol. Energy, Vol. 148, pp. 128-139, 2017.

[16] C. C. Ahmed, M. Cherkaoui, and M. Mokhlis, "PSO-SMC controller based GMPPT technique for photovoltaic panel under partial shading effect", International Journal of Intelligent Engineering and Systems, Vol. 13, No. 2, pp. 307-316, 2020, doi: 10.22266/ijies2020.0430.30

[17] A. F. Mirza, M. Mansoor, and Q. Ling, "A novel MPPT technique based on Henry gas solubility optimization", Energy Convers. Manag., Vol. 225, No. September, p. 113409, 2020.

[18] I. Shams, S. Mekhilef, and K. S. Tey, "Improved-Team-Game-Optimization-

Algorithm-Based Solar MPPT with Fast Convergence Speed and Fast Response to Load Variations", IEEE Trans. Ind. Electron., Vol. 68, No. 8, pp. 7093-7103, 2021.

[19] K. N. Nwaigwe, P. Mutabilwa, and E. Dintwa, "An overview of solar power (PV systems) integration into electricity grids", Mater. Sci. Energy Technol., Vol. 2, No. 3, pp. 629-633, 2019.

[20] S. S. Kumar, G. Dharmireddy, P. Raja, and S. 
Received: October 20, 2021. Revised: January 23, 2022.

Moorthi, "A voltage controller in photo-voltaic system without battery storage for stand-alone applications", InECCE 2011 - Int. Conf. Electr. Control Comput. Eng., No. December 2015, pp. 269-274, 2011. 